\title{
Analysis of the braking longitudinal force considered by NBR7187 (2003) through a case study
}

\section{Análise da força longitudinal devida à frenagem considerada pela NBR7187 (2003) através de estudo de caso}
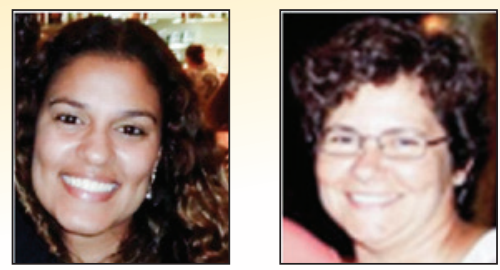

G. C. BETTAZZI

giadabettazzi@gmail.com

T. B. DUMÊT a

tbdumet@ufba.br

\begin{abstract}
This paper analyzed the mechanical behavior of a railway bridge by the Finite Element Method and by monitoring strain deformations with extensometry during its operation. To represent the situations that occur in its operation, tests were made with train braking. The results of monitoring the bottom cross section of column P15 of the bridge are presented. Based on the obtained data, the deformations occurring during the tests are verified against the calculated values obtained by the FEM method and those prescribed by NBR 7187(2003). The comparison between the real behavior of the structure, recorded experimentally through extensometry, and the numerical forecast and its assumptions from the project conceived was done. From this comparison, it verified that the value of longitudinal force due to braking recommended by the standard is appropriate.
\end{abstract}

Keywords: railway braking. railway bridge. NBR 7187 (2003). extensometry. bridges.

\section{Resumo}

Neste trabalho foi analisado o comportamento mecânico de uma ponte rodoferroviária com o cálculo através do Método dos Elementos Finitos e com o monitoramento com extensometria das deformações obtidas durante sua operação. Para representar as situações que ocorrem em sua operação, foram feitos testes com frenagem de trem. São apresentados os resultados do monitoramento da seção transversal da base do pilar P15 da ponte. Com base nos dados obtidos, foi verificado se as deformações ocorridas durante os testes estão ou não de acordo com o calculado pelo método numérico e o prescrito na norma NBR 7187(2003). Foi feita a comparação entre o comportamento real da estrutura, registrado experimentalmente através da extensometria, e a previsão numérica a partir do projeto idealizado. A partir dessa comparação, verificou-se se o valor da força longitudinal devida à frenagem recomendado pela norma está adequado.

Palavras-chave: frenagem ferroviária. ponte rodoferroviária. NBR 7187 (2003). extensometria. pontes. 


\section{Introduction}

A structure's integrity should be analyzed regularly throughout its lifespan to avoid potential problems caused by geometric flaws, differential foundation settling, and design or construction errors. Non-destructive methods are the best way to ensure the absence of structural problems because, as the name implies, they do not damage the structure. One such method is extensometry, which is a technique for monitoring strain. In this study, extensometry was used on a railway bridge.

The train traffic on a bridge causes stresses in the structure that can be calculated from the strain data at previously defined points. The moments and loads that cause these deformations can be calculated from the geometric data of a cross section.

The main reason for monitoring braking is to determine the stress transmitted to the mechanical anchors installed at the anchor points of a mixed-structure bridge.

When a train is passing over a bridge, the superstructure's sections work alternately under tensile and compressive loading as the train arrives at subsequent sections of the bridge.

Due to the alternating forces along the bridge, it is necessary to monitor the strains in strategic sections throughout testing, and extensometry is used for this purpose.

Extensometry is a technique used for experimental measuring and the recording of strains and stresses in metal or reinforced concrete structures under loading or thermal gradients, among other uses. The strain in several parts of a real structure, under service conditions, can be measured with accuracy and without damaging the structure while maintaining the loads under stress levels compatible with its bearing capacity. This measurement allows for a quantitative analysis of the strain distribution under real operating conditions. In the elastic region of a given material's stress-strain diagram, with the strain being directly proportional to the deformation, it was possible to determine the stress at a given section of a structural element by using the measured strain multiplied by the material's modulus of elasticity (E).

With these data, it was concluded that extensometry made it possible to monitor the stress distribution variation along the sections of a bridge during its operation based on the measured and digitally recorded strain values.

To analyze the structure's theoretical behavior and compare the calculated strain values with those measured using extensometry,

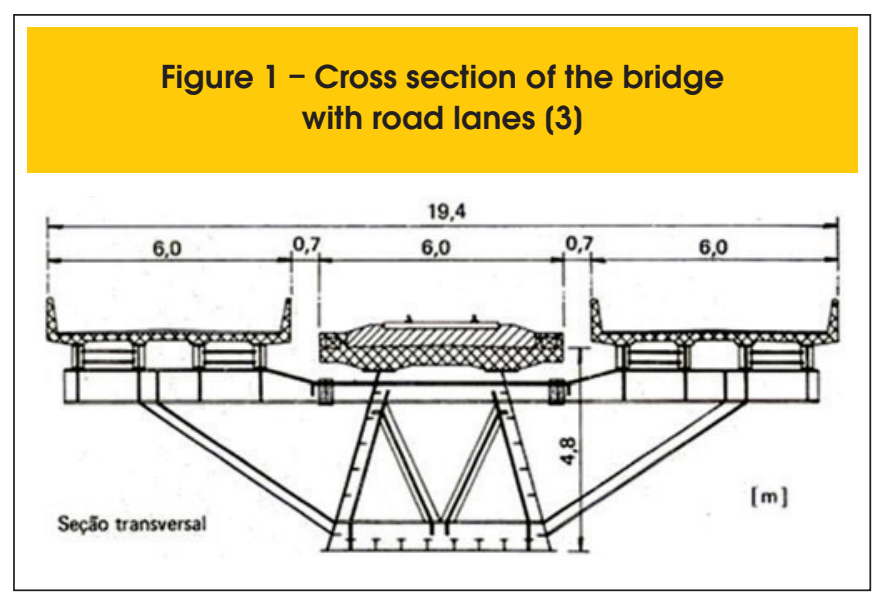

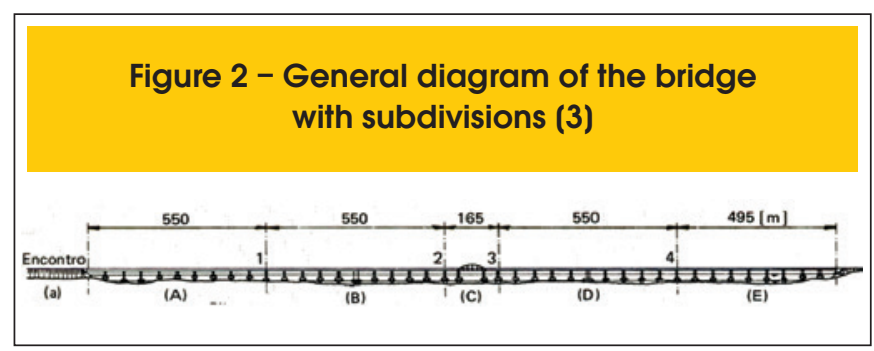

it was necessary to calculate the stresses and strains using a numerical method. The method used in this study is known as the finite element method (FEM).

The road and railway bridge studied is part of a railroad responsible for the operation of the longest train in the world, which is over three kilometers long. This train is used mainly to transport iron ore and manganese ore in addition to passengers. The bridge has a total width of $19.40 \mathrm{~m}$ and total length of 2,344 m, and its superstructure is defined by a single-celled metal box topped by a concrete deck, pre-stressed in its longitudinal direction and operating in a composite manner. The box is $6.00 \mathrm{~m}$ wide, on which the entire rail bed sits.

In addition to a railroad, the bridge also contains a state highway. The lateral road lanes are built on angle bars attached by screws to the central box, supporting metal cross beams every $11 \mathrm{~m}$, which in turn are topped by decks containing composite beams. The box's slab is also pre-stressed. The total width of each road section is $6.00 \mathrm{~m}$, including guardrails (see Figure 1).

The monitored structure consisted of a road and railway bridge subdivided into 5 sections with lengths of 550 m, 550 m, 165 m, $550 \mathrm{~m}$, and $465 \mathrm{~m}$, totaling 2,344 m of length. All spans were 55 $\mathrm{m}$ long, except for the 165-m section, which had a central span of $77 \mathrm{~m}$ in length over a navigable channel and was equipped with an auxiliary upper arch with adjacent spans of $44 \mathrm{~m}$ each. The bridge had, in the railway portion, a metal box central section (special anti-corrosion steel SAC-50, Class II) with a reinforced concrete deck in the span and pre-stressed on the support, characteristic of a composite structure. The highway lanes were constructed using the angle bar process and mixed grill and were fixed at transversely stiffened points of the box.

The columns were composed of reinforced concrete with cellular cross sections and were made with sliding molds [3].

The bridge was built using the incremental launch method, where the entire superstructure, with previously built columns, was longitudinally pushed by means of special jacks capable of providing both horizontal and vertical movement.

Figure 2 shows a schematic overview of the bridge. Letters $(A)$ to (E) refer to sections 1 to 5 , respectively.

Section 2, the modeled section, is $550 \mathrm{~m}$ long from the expansion joint of column P10 to the expansion joint of column P20. The fixed anchorage point of the longitudinal forces of this section is column P15 (monitored column), $21.85 \mathrm{~m}$ high, with a hollow cross section with external dimensions of $10.00 \mathrm{~m} \times 7.50 \mathrm{~m}$ and internal walls that define eight chambers. These dimensions provide significant column bearing capacity to resist shear forces and bending moments arising from the braking and acceleration forces from both the railway and the highway.

Columns P11 to P14 and P16 to P20 have hollow cross sections with external dimensions of $6.00 \mathrm{~m}$ by $1.50 \mathrm{~m}$. The columns' faces 
that cross-cut the river are rounded to minimize the current forces and hinder the trapping of floating objects, with heights ranging between $23 \mathrm{~m}$ and $24 \mathrm{~m}$.

The anchoring system of column P15 is formed by studs and shear wrenches responsible for the transfer of longitudinal forces from the superstructure to the column.

\subsection{Objectives}

This study's main objective was to analyze the mechanical behavior of a road and railway bridge by monitoring the strain occurring in the cross section of the base of a bridge column during its operation.

The specific goals of this study were to analyze the stress distribution in the monitored section during its operation, analyze the theoretical behavior of the bridge structure when under the influence of known loads according to the standard NBR 7187 (2003), and verify whether the value of the longitudinal force due to braking, given by the standard, was appropriate.

\subsection{Background}

There are times when the understanding of a railway bridge's bearing capacity becomes necessary so that trains with increased loads (i.e., heavier wagons or greater lengths) can travel over it safely. The bearing capacity of a railway bridge can be determined by testing, provided there is a train with defined features on a determined section of the thoroughfare.

However, in addition to the difficulty of having a train and a commercial thoroughfare available for testing, this procedure is often not feasible because, as in the case of a railway system, a train or a thoroughfare still in the design stage does not exist. Moreover, when investigating the speed limit for existing trains, certain testing conditions can lead to loss of control of the train, with consequent risks and losses.

Thus, there has been a need for a reliable simulation process that allows the necessary tests for a given system's optimization to be carried out rapidly and safely, or for various possible conditions to

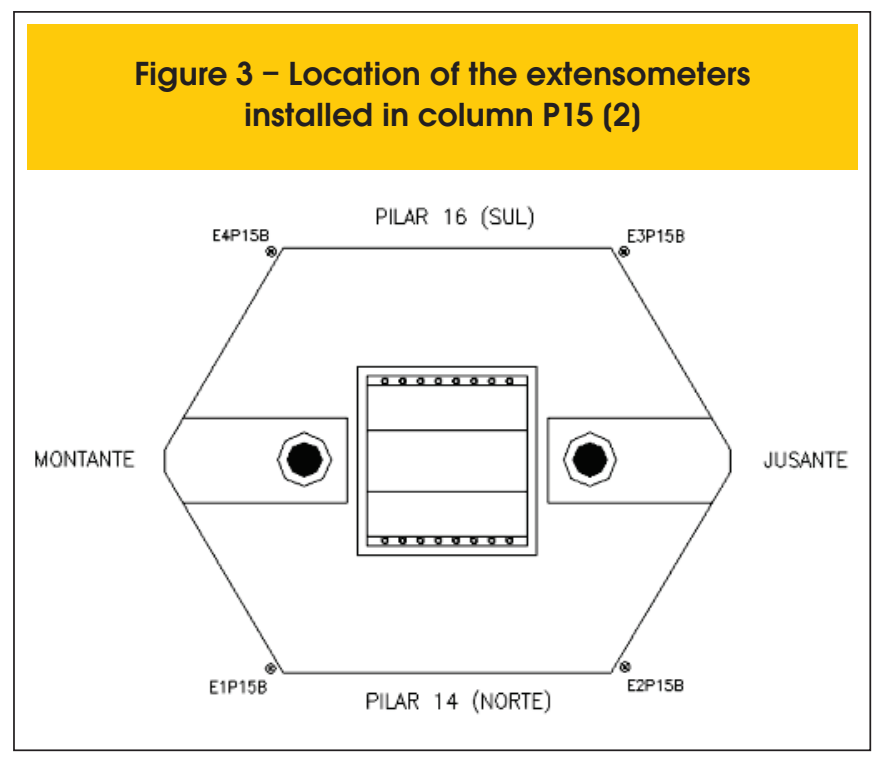

be simulated so that the most appropriate solution can be selected. However, this simulation process is no more accurate than performing actual tests with a train possessing the necessary characteristics and a study thoroughfare. This article highlights the difficulty of accomplishing the tests described in this study. The tests required complex logistics so that their completion would interfere minimally with the railroad's operation.

In addition, this study conducted tests using the train considered the longest in the world, which made those tests even more significant. No record has been identified in the scientific literature concerning the extensometry monitoring of a road and railway bridge during the passing and braking of trains with variable loads and speeds. Thus, the analysis and publication of such data will be of utmost importance to the technical community with respect to bridge design because the work presents the foundation for a discussion about the value recommended by the Brazilian standard for the load due to train braking.

\subsection{Methodology}

The methodology used to establish the actual distribution of stresses in the bridge column section during its operation was intended to analyze the measured strains and then, knowing the modulus of elasticity of the steel used in the structure's construction, to calculate the respective stresses.

To analyze the bridge's theoretical behavior, these stresses were calculated using FEM by introducing the geometrical characteristics of the materials, loading, and movement restrictions in the model created to represent the bridge structure.

Only one of the bridge's five sections was modeled (section 2 ) because each section operated independently from the others. The chosen section exhibited fewer modeling difficulties compared to the others in terms of the auxiliary arch and abutment locations.

The bridge's monitoring was conducted through the installation of electric extensometers on the reinforcing steel of the concrete columns. Data acquisition was performed using data acquisition systems and software provided by Lynx Tecnologia. The software used for data acquisition and subsequent processing was AqDados ${ }^{\circledR}$, and the signal analysis and processing module in that software is called AqDAnalysis ${ }^{\circledR}$, version 7.2. The data acquisition system for monitoring was the ADS2000 model with an AI2161 conditioner.

Figure 3 shows the location of the extensometers whose strains were analyzed in this study, those installed in abutment column P15. The following procedure was followed to install the extensometers on the column reinforcements.

a) Determination of the position of the steel rebar to be instrumented with a pachometer

b) Delimitation of the concrete area to be removed with a marble cutter

c) Removal of the concrete covering layer with a chisel or jackhammer

d) Sanding of the rebar, to remove dents, with an electric sander

e) Manual sanding of the rebar with sandpaper

f) Cleaning of the rebar with isopropyl alcohol

g) Placement of the electrical resistance extensometer with cyanoacrylate ester adhesive (super glue)

h) Welding of the cables with a three-wire connection

i) Electrical insulation of the wiring with electrical tape

j) Mechanical protection with epoxy resin adhesive 
Table 2 - Height of section 2 columns

\begin{tabular}{|cc|}
\hline Column & Height $(\mathrm{cm})$ \\
\hline P10 & 2326.3 \\
P11 & 2398.8 \\
P12 & 2402.9 \\
P13 & 2405.0 \\
P14 & 2405.0 \\
P15 & 2185.0 \\
P16 & 2405.0 \\
P17 & 2405.0 \\
P18 & 2405.0 \\
P19 & 2405.0 \\
P20 & 2405.0 \\
\hline
\end{tabular}

k) Verification of the extensometer's operation with a multimeter and data acquisition system

I) Closure of the gap with grout

The tests cited in this study occurred in stages. The trains passed and braked on the bridge at different speeds and loads. Furthermore, the composition of the trains (type and number of wagons and locomotives) also differed throughout the tests and assays. Because the bridge experienced a high flow of material and passenger transportation, such tests and assays were planned to minimize the time losses caused by the braking and speed changes. The speeds of the trains did not exceed the railroad's minimum and maximum operating speeds (as defined by the company responsible for the railway) so as not to cause damage to the bridge structure or to the locomotives. The stresses verified in the section under study were compared with those calculated by numerical analysis, taking into account the stresses prescribed by the NBR 7187(2003) standard and, whenever possible, understood from theoretical considerations based on the technical literature.

To calculate the theoretical strain values according to the NBR7187 (2003) considerations, section 2 of the bridge was modeled in software that used the FEM in its calculations. The software used in this study was selected for its ease of handling and for being a program widely used in bridge design. The use of specific bridge software was not necessary because this study did not aim to design a bridge, only to perform a simple analysis of an existing bridge.

For this study to be successful, it was necessary to make simplifications that significantly reduced the time spent on modeling and minimized interference in the analyzed results.

Because the bridge is composed of five structurally independent sections, it was not necessary to model the entire bridge, and only one section was modeled. Section 2 was chosen as the easiest section to be modeled because it does not have abutments, such as in sections 1 and 5 , nor an arch, such as in section 3 . Section 4 could have been chosen for having one fewer span than section 2 , but only one column of this section was monitored.

Once the section to be modeled was chosen, the modeling commenced with the variable height columns, as observed in Table 2 . The columns were represented by bars with their moment of inertia value defined according to the column cross-sections, shown in Figure 4.
The superstructure of the bridge was also modeled as a bar. Similarly, this bar had its moment of inertia value calculated for the metal box and the concrete deck. It was not necessary for the bars to have the same weight as the bridge elements because this load did not affect the strain variation during train braking.

To represent the elastometer-type support devices on top of the columns, the connection between the columns and the metal box was modeled to allow for rotation between the box and columns. Thus, there was no encasement between the box and the columns. After section 2 was modeled, the horizontally distributed load relative to the braking was included throughout the section, considering a slowdown of $15 \%$ as recommended by NBR7187 (2003). The train-type to be considered was the TB360, taken from the standard, and the impact coefficient was equal to 1.28 .

The main objective of this study was to compare the calculated strains with the measured strains. To this end, a comparison was made considering the same situation in both the model and the real structure. The presented graphs refer only to the time when the train was passing and braking while loaded on the monitored section. Because the time the train took to pass through a section was at most 10 minutes, the only relevant loads with varying values were the braking load and that due to the train's weight. Therefore, only these loads were included in the model created in the software. In this way, the strain variations were compared between

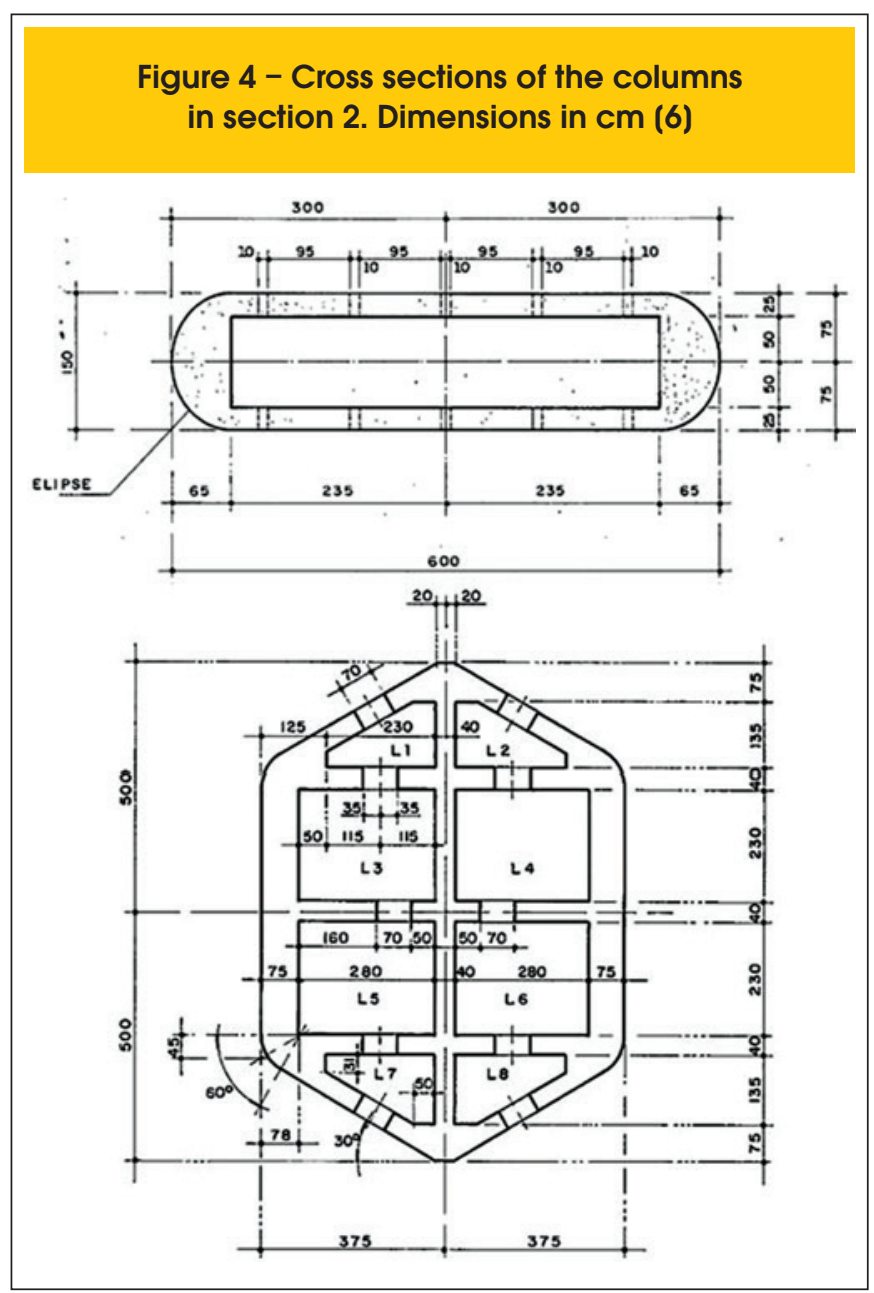


the instant when there was no train on the section and the instant when the train filled the entire section, which is the time when the greatest strains occurred.

A centrifugal load does not act on the bridge because there is no curve in section 2 . It was noted that, during the time represented in the graphs, the wind did not cause a relevant effect on the base of the columns, and neither did the temperature because there was not enough time for a major variation to occur. The other loads did not vary during monitoring, so they did not influence the measured strain variations and were therefore not included in the model. The loads related to passing vehicles on the highway were disregarded because the vehicles that travel there, when compared to the trains, exert very little influence on the measured strains. This situation was verified during testing. Finally, the side impact was not considered because it was a load transverse to the axis of the bridge that did not interfere with the bending moment in the analyzed direction, depicted as direction y.

After the structure of section 2 was modeled and the loads entered, the analysis was performed and the bending moment value at the base of the bars that represent the columns was extracted. To calculate the strain caused by the bending moment in the software, the normal stress was calculated, followed by the resulting strain.

The performed analysis was elastic because the stresses along the section were not greater than the yield strength. Therefore, the calculations were performed using Hooke's Law, which is confirmed below. The moments of inertia of the sections shown in the mentioned figures were calculated before including the bars in the model. The longitudinal direction (the direction of vehicle flow) was relevant to the analysis. Columns P10 to P14 and P16 to P20 had a moment of inertia of $1.15 \mathrm{~m}^{4}$, while the fixed column P15 had a moment of inertia of $143.7 \mathrm{~m}^{4}$

The concrete used to manufacture the columns had a value defined in the design of the characteristic compressive strength, with $\mathrm{f}_{\mathrm{ck}}$ equal to $25 \mathrm{MPa}$. In assessing the behavior of a structural element or cross section, a single modulus of elasticity can be adopted for both tension and compression, equal to the secant modulus of elasticity, which is calculated using Equation 1 [7]:

$$
\mathrm{E}_{\mathrm{cS}}=0.85 \cdot 5,600 \sqrt{\mathrm{f}_{\mathrm{ck}}}=0.85 \cdot 5,600 \cdot \sqrt{25}=23,800 \mathrm{MPa}
$$

Thus, the modulus of elasticity value used for the calculation of the column stiffness was equal to $23,800 \mathrm{MPa}$.

The braking force included in the bridge model developed in the software accounted for $15 \%$ of the vertical load of the type TB360 train used in the transportation of iron ore, as shown in Equation 2:

Frenagem $=360 * 4+120 *(550-8) * 0.15=9,972 \mathrm{kN}$

The strain variation value was calculated from the bending moment extracted from the diagram generated by the finite element software.

\section{Results and discussion}

This study was conducted between November 2011 and August 2012 by AJL Engenharia and was based on the results obtained from monitoring the strain in sections of the road and railway bridge, as along with numerically calculated strain values and those from a literature review.

Figure 5 shows graphs of the rebar strain versus time obtained

\section{Figure 5 - Strain graphs of the four extensometers installed in column P15 during the train's braking (2)}
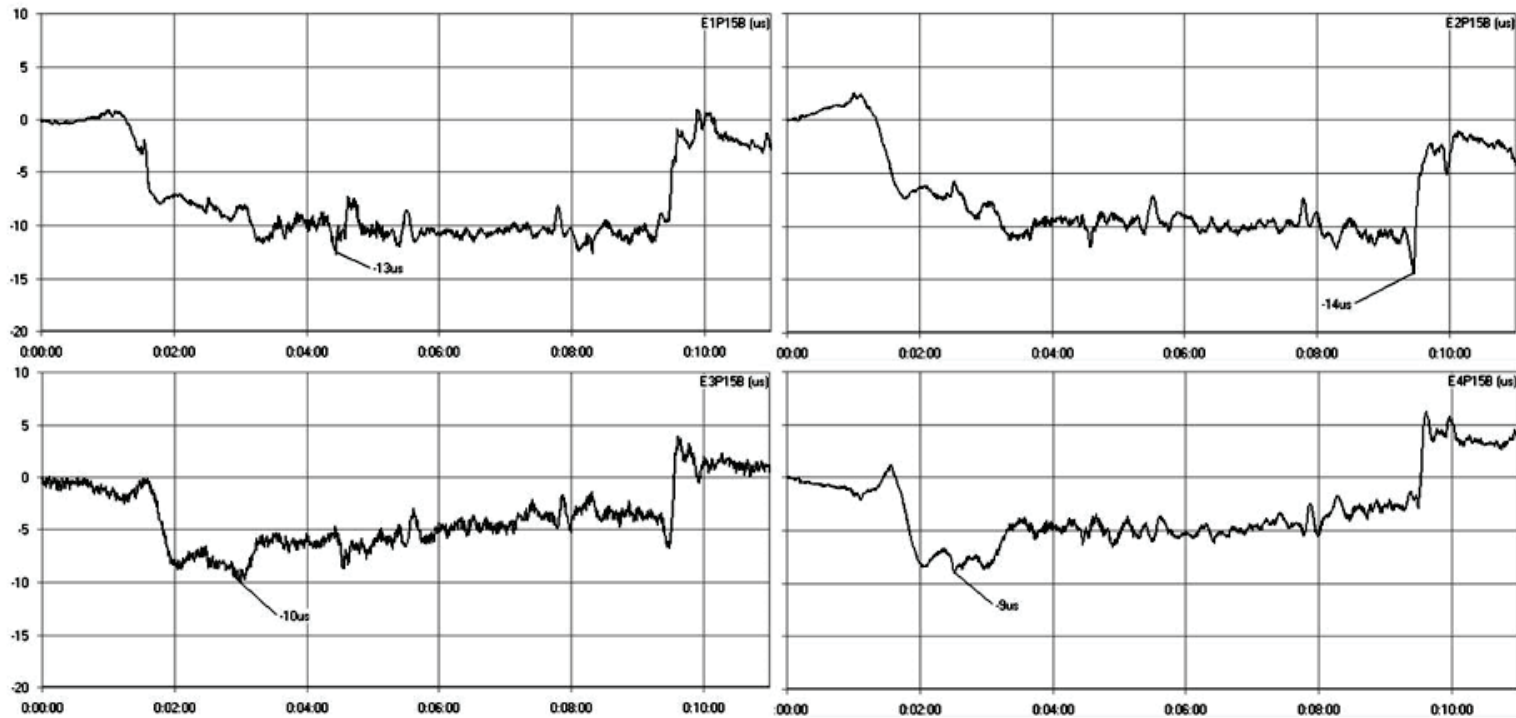
Table 1 - Summary of the strain and stress variations in the extensometers at column P15

\begin{tabular}{ccc|}
6 Extensometer & $\begin{array}{c}7 \text { Strain variation } \\
(\Delta \varepsilon)\end{array}$ & $\begin{array}{c}8 \text { Stress variation } \\
(\Delta \sigma)\end{array}$ \\
9 E1P15B & $10-13 \mu$ & $1126 \mathrm{MPa}$ \\
$12 \mathrm{E} 2 \mathrm{P} 15 \mathrm{~B}$ & $13-14 \mu$ & $1428 \mathrm{MPa}$ \\
$15 \mathrm{E} 3 \mathrm{P} 15 \mathrm{~B}$ & $16-10 \mu$ & $1720 \mathrm{MPa}$ \\
$18 \mathrm{E} 4 \mathrm{P} 15 \mathrm{~B}$ & $19-9 \mu$ & $2018 \mathrm{MPa}$ \\
\hline
\end{tabular}

from the monitoring performed on the road and railway bridge. The graphs' ordinates are the specific strain values in $\mu$ and the abscissae are the time lengths, in minutes, of the trains passing over the column. The graphs start at zero so that the analysis is simpler and faster, presenting the strain variation relative to the beginning of the graph without any confusion. In addition, the graphs refer only to the time of the passing train because earlier or later readings were not relevant to this study. These graphs show the strains measured by the extensometers installed in the cross-section located two meters from the base of column P15 during the braking of a loaded train with a total weight of 39,282 tf. Strain variation values were extracted from the graphs, and the corresponding stress values were calculated and are summarized in Table 1.

Table 1 shows that the strain variation values in extensometers 1 and 2 differ by $-1 \mu$, as do the values of extensometers 3 and 4 .

Moreover, based on the knowledge of the extensometer positions, one could infer the direction of the braking force as being from column P16 to column P14 because only in this direction would it be possible to cause a greater deformation due to higher compression in extensometers 1 and 2. This direction was correct because these graphs were generated by monitoring the braking of a loaded train, which occurred only in the direction Abutment E2 $\rightarrow$ Abutment E1 so that the iron ore could be exported to the port. The strain variations shown in the table were the result of a) vertical loading due to the weight of the train and the iron ore it transported and $b$ ) horizontal loading due to train braking. The following procedure was conducted to calculate the amount of strain resulting from the bending moment.

1. Three extensometers were selected $\left(\mathrm{E} 1 \mathrm{P} 15 \mathrm{~B}-\varepsilon_{1}\right.$, E2P15B $\varepsilon_{2}$, and E3P15B $-\varepsilon_{3}$ );

2. A system of equations was assembled with the strain variations presented by the selected extensometers, where the unknown variables were the portions due to the normal force $\mathbf{b}$, the bending moment in the direction transverse to the axis of bridge, $\mathbf{c}$, and the bending moment in the longitudinal direction of bridge $\mathbf{a}$. The system shown was assembled based on Figure 6, which shows diagrams of the strain values due to forces acting on column P15's cross-section with the arrangement of the extensometers:

$$
\left\{\begin{array}{l}
-a-b+c=\varepsilon_{1}-13 \\
-a-b+c=\varepsilon_{2}-14 \\
a-b+c=\varepsilon_{3}-10
\end{array}\right.
$$

Figure 6 - Strain graphs due to the normal force and bending moments in column P15

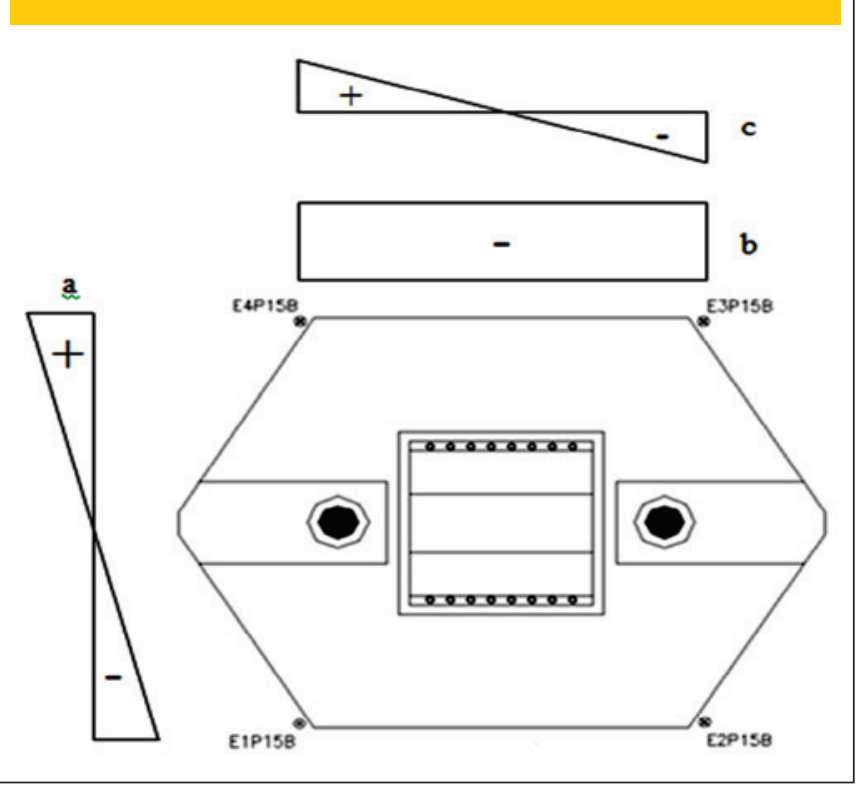

3. The system of equations was solved, resulting in $a=2.0 \mu, b=$ $11.5 \mu$, and $c=0.5 \mu$, with a ratio of $1 / 4$ between the strain caused by the transverse bending moment and the strain caused by the longitudinal bending moment.

This ratio of $25 \%$ among the strain values showed that the longitudinal bending moment was 4 times greater than the transverse bending moment, confirming that the forces in the longitudinal direction of the bridge were greater than the forces in the transverse direction of the bridge at the time monitored.

After the strain due to the bending moment was calculated, the corresponding stress could be calculated by multiplying it by the CA50 steel's modulus of elasticity, $E=200 \mathrm{GPa}$, resulting in a stress $\sigma=0.4 \mathrm{MPa}$.

Based on the diagram presented by the software, the bending moment value due to braking $2 \mathrm{~m}$ from the base of column $\mathrm{P} 15$ was found to be $197,932 \mathrm{kNm}$. This value was due only to the braking load because the connection between the column and the superstructure was pivoted, meaning there was no transfer of momentum between the two. Thus, the momentum caused by the vertical load of the train type was not transmitted to the column. Using equation 3 , the corresponding normal stress was calculated with the data from the concrete section:

$$
\sigma=\frac{\mathrm{M} \cdot \mathrm{y}}{\mathrm{I}}=\frac{197,932 \mathrm{kN} \cdot \mathrm{m} \cdot 3.75 \mathrm{~m}}{143.7 \mathrm{~m}^{4}} \cong 5,165 \mathrm{kN} / \mathrm{m}^{2}=5 \mathrm{MPa}
$$

Based on the normal stress exerted on the reinforcement farther from the centroid, the specific strain was calculated using Equation 4:

$$
\varepsilon_{\text {theoretical }}=\frac{\sigma}{\mathrm{E}}=\frac{5,165 \mathrm{kN} / \mathrm{m}^{2}}{200 \cdot 10^{6} \mathrm{kN} / \mathrm{m}^{2}} \cong 26 \cdot 10^{-6}=26 \mu
$$


Thus, the strain anticipated during the braking of the TB360 train $2 \mathrm{~m}$ from the base of column P15 was equal to $26 \mu$. The strain variation value due to the bending moment measured by the extensometers installed in four of the six corners of column P15 was compared with $\varepsilon_{\text {theoretical }}=26 \mu$.

The highest bending moment value $\mathrm{M}$ in the metal box due to the TB360 train was $58,073 \mathrm{kNm}$. The moment of inertia around $x I_{x}$ calculated for the metal box and considering the concrete of the composite structure, was $2.43 \mathrm{~m}^{4}$, the position of the neutral axis $y$ was $3.24 \mathrm{~m}$, and the area A was $0.7 \mathrm{~m}^{2}$. Finally, the normal stress caused by this bending moment was calculated using Equation 5:

$$
\sigma=\frac{\mathrm{M} \cdot \mathrm{y}}{\mathrm{I}}=\frac{58,073 \cdot 3.24}{2.43} \cong 77,431 \mathrm{kN} / \mathrm{m}^{2} \cong 77 \mathrm{MPa}
$$

Considering the horizontal braking force of 9,972 kN applied on top of the rails, the normal stress was equal to:

$$
\sigma=\frac{9,972 \mathrm{kN}}{0.7 \mathrm{~m}^{2}}+\frac{9,972 \mathrm{kN} \cdot(4.83 .24) \mathrm{m}}{2.43 \mathrm{~m}^{4}}=\frac{20,648 \mathrm{kN}}{\mathrm{m}^{2}}=20.6 \mathrm{MPa}
$$

The yield stress of the USI-SAC-350 steel used to manufacture the metal box was $350 \mathrm{MPa}$. The highest normal stress exerted on the metal box $(98.1 \mathrm{MPa}$ ) was approximately $28 \%$ of the yield stress, and the stress values in the other 10 columns were irrelevant. Thus, the application of Hooke's Law in the calculations was justified.

The measured strain variation value was $\Delta \varepsilon=2 \mu$, equivalent to a moment $\mathrm{M}=15,328 \mathrm{kNm}$ from a braking force of $772 \mathrm{kN}$, which corresponded to only $7.7 \%$ of the value calculated by the Brazilian standard.

It was noted that the calculated strain variation value was approximately 13 times the measured strain variation value, confirming the initial question about the exaggerated braking force value considered by the NBR7187 (2003) standard.

It is worth noting that the train used in the test is the longest in the world, with 330 cars. Nevertheless, the strains measured during the braking of this train on the bridge were nowhere near the strains calculated according to NBR7187 (2003).

Another significant observation is that the train braked on the bridge without reducing its speed to zero. Therefore, it did not apply the emergency brakes, which would have induced a greater load on the abutment column due to the greater braking force. This action was not possible due to the limitations of the railway operating logistics.

It is also necessary to emphasize that, in reality, train braking occurs in a distributed manner because braking is not solely the responsibility of the locomotives but also of the wagons.

\section{Conclusions}

The following points list the main findings of this study.

- A $1200 \%$ difference was identified among the strain values calculated by the finite element software according to the requirements of NBR7187 (2003) and the strain values measured by the extensometry monitoring in the abutment column corner re- inforcements of section 2 due to the trains braking on the road and railway bridge. This result was due to the standard's use of $15 \%$ of the train-type load as the braking force, a value that was exaggerated even when compared with strains measured during the passing of a train with many wagons.

- The expected values for the strains in the design phase were always greater than the measured strain values because a series of simplifications were performed during the design due to the complexity of the loading to which the bridge was subjected. However, the calculated values in this study exceeded the exaggerated measured values, indicating that NBR7187 (2003) should be revised so that Brazilian bridges can be designed more efficiently, with greater material savings, because the calculated forces were lower and closer to the measured values.

- It was concluded that the NBR7187 (2003) standard for the longitudinal force due to braking was inadequate, requiring further analysis with the performance of more tests that can give an experimental basis for the development of a new theoretical method to calculate this force.

- The braking force calculated by AREMA [4] for this bridge design was $9,825 \mathrm{kN}=\left(200+17.5^{\star} 550\right)$ for section 2 . If Eurocode EN1991-2 [5] were used, the braking force value would be $20 * 550=11,000 \mathrm{kN}$. It was found that the braking force calculated by the Brazilian standard NBR7187 (2003) analyzed for this study was close to those calculated by the American standard and the European standard. Therefore, if the braking force calculated by the Brazilian standard has proved exaggerated in its conservatism, the values calculated using the other standards mentioned here, despite using other formulations to achieve the values, are also exaggerated in their calculations.

\section{Acknowledgements}

The authors gratefully acknowledge the financial support that enabled the elaboration of the dissertation from which this article originated, given by the Brazilian Federal Agency for the Support and Evaluation of Graduate Education (Coordenação de Aperfeiçoamento de Pessoal de Nível Superior - CAPES), and to AJL Engenharia, the company responsible for the monitoring of tests on the bridge and for providing the data used.

\section{References}

[01] AGÊNCIA NACIONAL DE TRANSPORTES TERRESTRES (ANTT) - Transporte Ferroviário [Railway Transportation]. Available in: <http://www.antt.gov.br/passageiro/apresentacaopas.asp> Accessed on: Dec 9, 2011.

[02] LEITE, Antônio João Fraga Pereira. Monitoramento com extensometria da ponte sobre o rio... - Relatório Técnico [Extensometry monitoring of the bridge over the river... - Technical Report]. Salvador, 2011.

[03] MASON, Jayme; CASTRO, Fernando Cardoso de. Ponte sobre o rio... Publicação Técnica da Companhia Vale do Rio Doce [Technical Publication of Companhia Vale do Rio Doce]. Vol. 7, n² 24., June, 1986.

[04] AMERICAN RAILWAY ENGINEERING AND MAINTENANCE-OF-WAY ASSOCIATION (AREMA) - Manual for Railway Engineering. Lanham, 2012. v. 2. 
[05] COMITÉ EUTOPÉEN DE NORMALISATION. EN 1991-2: Eurocode 1: Actions on structures - Part 2: Traffic loads on bridges. Brussels, 2002. $162 \mathrm{pp}$.

[06] MASON, Consultoria e Projetos Ltda. Plantas diversas [Various blueprints]. 1982.

[07] ASSOCIAÇÃO BRASILEIRA DE NORMAS TÉCNICAS (ABNT), NBR 6118 (2007) - Projeto de estruturas de concreto armado - procedimento [Design of reinforced concrete structures - procedure]. Rio de Janeiro, 2007. 